\title{
Ajaran tentang Bakti Istri kepada Suami dalam Serat Wulang Reh Putri
}

\author{
Mirya Anggraeni dan Suyanto \\ Fakultas Ilmu Budaya Universitas Diponegoro \\ Email: mememirya@gmail.com dan suyanto@undip.ac.id
}

\begin{abstract}
Educating literature is a literary genre that contains teachings, whether about behavior in society or teachings on how to reach perfection of life according to Javanese tradition. One of the literary texts of educating (piwulang) is Serat Wulang Reh Putri (SWRP) by Paku Buwana IX from Surakarta. The work contains educational values for women, especially for wifes. This teaching was imparted to women since childhood. The teachings in the text emphasize the importance of women to obey husbands. A wife according to SWRP must obey the command and prohibition of husband, respect and devoted to the husband also and must know the character of her husband. Therefore, married to a woman does not rely on physical beauty but kindness.
\end{abstract}

Keywords: teaching, women/wife, obedience, devotion, husband.

\section{Intisari}

Sastra piwulang adalah genre sastra yang berisi ajaran, baik tentang perilaku di masyarakat atau ajaran mengenai cara menggapai kesempurnaan hidup menurut tradisi masyarakat Jawa. Salah satu teks sastra piwulang adalah Serat Wulang Reh Putri (SWRP) karya Paku Buwana IX dari Surakarta. Karya tersebut berisi nilai-nilai edukasi bagi kaum perempuan terutama bagi para istri. Ajaran ini ditanamkan kepada para perempuan semenjak masih anak-anak. Ajaran dalam teks tersebut menekankan pentingya perempuan untuk patuh kepada suami. Seorang istri menurut SWRP harus taat pada perintah dan larangan suami, hormat dan mengabdi kepada suami pula serta harus mengetahui watak suaminya. Karena itu, berumah tangga atau bersuami bagi perempuan bukan mengandalkan kecantikan fisik tetapi kebaikan hati.

Kata Kunci: ajaran, perempuan/istri, taat, mengabdi, suami.

\section{Pendahuluan}

Pada masa kerajaan Mataram (Surakarta) ditemukan genre sastra yang disebut sastra piwulang. Sastra piwulang adalah genre sastra yang berisi ajaran, baik tentang perilaku di masyarakat atau ajaran mengenai cara menggapai kesempurnaan hidup. Biasanya sastra piwulang digubah oleh tokoh-tokoh yang memiliki wibawa besar di dalam tradisi sastra dan mitologi Jawa (Sudewa, 1991:17). Sastra piwulang banyak ditulis oleh Mangku Nagara IV. Karya-karya Mangku Nagara IV antara lain Serat Wedhatama, Serat Darmawasita, Serat Paliatma, Serat Wirawiyata, Serat Nayakawara, Serat Salokatama, Serat Sriyatna, dan Serat Warayagnya (Siswokartono, 2006: 227-260). 
Selain Mangku Nagara IV, tokoh lain yang menulis sastra piwulang adalah Paku Buwana IV. Salah satu ciptaannya adalah Serat Wulangreh. Karya ini merupakan ajaran etika yang ditulis oleh Paku Buwana IV. Serat ini ditulis berdasarkan keprihatinan raja Surakarta tersebut terhadap perkembangan zaman di masa itu. Banyak adat istiadat baru yang semula tidak dikenal akhirnya masuk ke istana. Sementara itu, generasi mudanya lebih terbawa ke arus baru daripada menaati dan menjalankan yang lama. Dengan demikian generasi muda dianggap kurang menghargai dan kurang menghormati adat istiadat dan nilai-nilai warisan leluhur, kurang sopan santun, kurang prihatin, dan tidak mau mendengarkan dan menerima pendapat orang tua. Karena alasan itulah Paku Buwana IV menggubah karangan yang berisi nilai-nilai etika di dalam Serat Wulangreh (Marsono dan Hendrosaputro, 1999: 346-347).

Contoh karya lain yang digolongkan dalam sastra piwulang adalah Serat Wulang Putra. Itu merupakan karya sastra Jawa klasik yang ditulis oleh Nyi Adisara, seorang pujangga wanita yang hidup pada masa Paku Buwana IV. Karya sastra ini memuat masalah etika Jawa (Marsono dan Hendrosaputro, 1999: 345-346).

Tokoh lain yang juga menulis sastra piwulang adalah Paku Buwana IX. Karyakaryanya antara lain Serat Wararatna, Serat Pituturing Estri, dan Serat Wulang Paku Buwana IX. Semua teks tersebut ditujukan kepada kaum perempuan. Dalam karya-karya itu diajarkan bahwa seorang perempuan harus menerima takdir dengan lapang dada. Oleh karena itu, segala tingkah lakunya harus dihiasi dengan hati riang (Suratno, 2006: $57)$.

Serat Wulang Reh Putri (selanjutnya disingkat SWRP) yang dijadikan objek penelitian ini merupakan salah satu sastra piwulang karya Paku Buwana IX. Karya tersebut berisi ajaran untuk para putri Paku Buwana IX. Tema SWRP dapat diketahui dengan mencari makna yang relevan yang sangat erat hubungannya dengan "keseluruhan yang organik" dalam SWRP. Tema SWRP merupakan pengejawantahan gagasan, ide, atau pikiran utama pengarang, yaitu Paku Buwana IX. Tema SWRP adalah ajaran (pendidikan) bagi putri raja, yaitu tentang seluk-beluk hidup berumah tangga. Pengarang ingin membentuk karakteristik sosok atau figur wanita (istri) yang ideal dalam perkawinan menurut pandangannya (Ratnawati, 2008: 48).

Perkawinan menurut pandangan SWRP adalah sesuatu yang sakral. Oleh karena itu, untuk menuju jenjang perkawinan seorang wanita perlu dibekali dengan pendidikan 
budi pekerti yang baik, tata krama dan tata susila dalam perkawinan, watak halus, taat, sabar pada suami, dan bakti kepada Allah. Semua ajaran itu merupakan nilai-nilai moral untuk perempuan dalam SWRP.

\title{
Pembahasan
}

\section{Pengabdian kepada Suami}

Salah satu nilai moral yang tercantum di dalam SRWP adalah pengabdian. Perempuan sebagai istri harus mengabdi kepada suami dapat dilihat di kutipan, pupuh Mijil, bait ke1 berikut.

\author{
Ingsun nulis ing layang puniki \\ atembang pamiyos \\ awarah wuruk ing wijile \\ marang sagung putraningsun estri \\ tingkahing akrami \\ suwita ing kakung
}

\section{Terjemahan:}

Saya menulis karya ini

dalam bentuk tembang

memberikan petuah dalam bentuk tembang mijil

kepada seluruh anak perempuan saya

tentang tata krama dalam perkawinan

mengabdi kepada suami

Kutipan SRWP, pupuh Mijil, bait ke-1 di atas berisi nilai moral yang harus dipegang oleh perempuan. Perempuan dalam melakukan perkawinan harus memahami tata krama dalam perkawinan. Perempuan yang tidak memahami tata krama secara otomatis disebut sebagai perempuan yang tidak bermoral.

\section{Ketaatan kepada Suami}

Nilai moral yang juga ditemukan pada SRWP adalah ketaatan. Seorang kepada perempuan dalam hidup berumah tangga agar taat kepada aturan. Nilai moral tersebut terdapat di kutipan $S R W P$, pupuh Mijil, bait ke-2 berikut. 
Nora gampang babo wong alaki

luwih saking abot

kudu weruh ing tata titine

miwah cara-carane wong laki

lan wateke ugi

den awas den emut

Terjemahan:

Tidak mudah orang bersuami

sangat berat

harus tahu aturan

juga harus tahu cara-cara orang bersuami

dan juga watak lelaki

waspadalah dan ingatlah

Pada kutipan SRWP, pupuh Mijil, bait ke-2 di atas terlihat bahwa nilai-nilai moral berkaitan dengan aturan perempuan menjalani pernikahan. Pemahaman istri terhadap hak dan kewajiban sebagai seorang istri kepada suami menuntut seorang perempuan dapat berperilaku dengan layak. Apabila seorang istri tidak berperilaku sesuai aturan, dia akan mendapat sanksi moral dari masyarakat yang ada di sekelilingnya.

\section{Penghormatan dan Bakti kepada Suami}

Seorang perempuan sebagai istri harus menghormati suami dan berbakti kepada suami. Jika istri tidak menghormati suaminya, ia berarti mencoreng muka orang tuanya. Ajaran SWRP tersebut berisi penjelasan bahwa jika seorang istri tidak menghormati suaminya, orang tuanya akan dituduh tidak mampu mendidik dan tidak dapat memberikan nasihat kepada anaknya. Dengan demikian, seorang perempuan disebut sebagai anak yang memiliki moral baik apabila dia dapat menjaga kehormatan orang tuanya. Hal itu dapat dilihat di kutipan SWRP, pupuh Kinanthi, bait ke-7 dan ke-8 berikut.

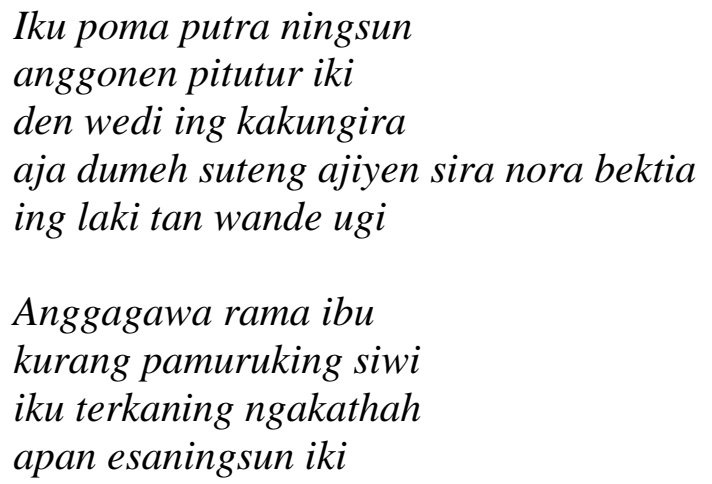


marang Allahu Taala
miwah ing Rasulullah

Terjemahan:

Inilah anakku

pakailah ajaran ini

takutlah kepada suami

jangan merasa takabur (sombong) sebagai putri raja

jika engkau tidak berbakti

kepada suami tidak urung juga

Membawa bapak ibu

kurang memberikan petuah pada anak

itu prasagka orang banyak

permintaanku ini

kepada Allah Taala

dan kepada Rasulullah

Apabila dicermati dari sifatnya, pupuh-pupuh tembang Macapat dalam seratserat piwulang SRWP itu adalah wacana argumentatif. Hal itu terlihat dari adanya berbagai argumen penulisnya (PB IX) untuk meyakinkan pembacanya (orang yang dinasihati) seperti tertulis di pupuh-pupuh tembang Macapat. Terlihat bahwa penulis berusaha meyakinkan pentingnya nasihat atau saran yang disampaikan sehingga yang dinasihati atau yang diberi saran itu menuruti nasihat atau saran itu. Wacana tersebut sifatnya serupa dengan wacana khotbah, sambutan, atau ular-ular. Orang yang memberikan nasihat, khotbah, atau ular-ular berusaha meyakinkan pendengar atau pembaca tulisan kotbah agar melaksanakan nasihat yang disampaikannya dengan memberikan gambaran akibat buruk seandainya nasihat yang disampaikan itu tidak dilaksanakan.

\section{Pengaruh Perubahan Budaya pada SWRP}

Isi SWRP menunjukkan bahwa pada masa penciptaannya pengarang sudah mempertimbangkan perubahan budaya yang menyangkut perilaku seorang perempuan. Perilaku perempuan yang dianggap berpaling dari budaya Jawa tersebut tidak terlepas dari pandangan yang salah terhadap budaya modern. Budaya modern yang sering salah diterjemahkan sebagai budaya 'bebas' menjadikan seorang perempuan berperilaku tidak selayaknya sebagai seorang perempuan. 
Perilaku yang 'tidak lazim' akibat pandangan yang salah terhadap budaya modern dicontohkan dengan perilaku seorang putri Raja Cina, Putri Adaninggar. Putri Adaninggar dalam naskah tersebut diceritakan melakukan perilaku yang sangat berlawanan dengan budaya yang sampai sekarang ini dipegang oleh perempuan Jawa. Dalam budaya Jawa, pihak lelaki yang melamar pihak perempuan untuk menjadi calon istri. Namun, dalam naskah tersebut diceritakan perilaku sang putri yang justru melamar pria pujaannya, Sang Jayengmurti. Perubahan budaya pada pensterotipan perempuan tersebut terlihat pada kutipan SWRP, pupuh Mijil, bait ke-4 berikut.

Pituture raja Cina dhingin

Iya luwih abot

Pamuruke marang atmajane

Dewi Adaninggar duk ngunggahi

Mring Sang Jayengmurti

angkate winuruk

Terjemahan:

Nasihat ratu Cina ini

Sangatlah berharga

Nasihat yang diajarkan kepada anaknya

Dewi Adaninggar ketika melamar

Sang Jayengmurti

ketika berangkat (dinasihati)

Kutipan SWRP, pupuh Mijil, bait ke-4 di atas mengajarkan kepada perempuan untuk berpikir lebih panjang sebelum melakukan suatu perbuatan. Sekali perempuan melakukan kesalahan, penyesalan sepanjang hiduplah yang akan dirasakannya. Kutipan tersebut berisi nasihat kepada perempuan untuk berbuat tidak sekadar untuk memperturutkan kata hati.

\section{Kesakralan Perkawinan}

Pernikahan adalah hal sakral yang tidak boleh dibuat main-main. Oleh karena itu, seorang perempuan harus mengetahui sejak dini bekal dan syarat perkawinan begitu memasuki jenjang perkawinan. Dengan demikian, seorang perempuan harus mempunyai bekal pengetahuan tentang perkawinan dan harus mampu memenuhi syaratsyaratnya.

Tentang bekal perkawinan yang harus dipenuhi perempuan terlihat di kutipan SWRP, pupuh Asmaradana, bait ke-1 dan ke-2 berikut. 


\section{Pratikele wong akrami \\ Dudu brana dudu rupa \\ Among ati paitane \\ luput pisan kena pisan \\ yen gampang luwih gampang \\ yen angel-angel kelangkung \\ tan kena tinambak arta}

\section{Tan kena tinambak warni \\ uger-ugere wong krama \\ kudu eling paitane \\ eling kawise seng priya \\ ora kenas embrana \\ kurang titi kurang emut \\ iku luput gambra-ambra}

\section{Terjemahan:}

Bekal orang menikah,

Bukan harta bukan pula kecantikan

Hanya berbekal hati (cinta)

sekali gagal, gagallah,

jika mudah terasakan amat mudah

jika sulit terasakan amat sulit

uang tidak menjadi andalannya

Tidak bisa dibayar dengan rupa

syarat-syarat orang berumah tangga

harus diingat modalnya

ingat kekuasaan laki-laki

tidak boleh seenaknya

kurang berhati-hati dan kurang waspada

kesalahan yang berlebihan.

Kutipan SWRP, pupuh Asmarandana, bait ke-1 dan ke-2 ditemukan nasihat untuk seorang perempuan sebelum menikah. Bekal yang harus dimiliki seorang perempuan untuk menjalani pernikahan adalah hati. Hati yang dimaksudkan adalah adanya rasa cinta yang tulus kepada pasangan. Ketulusan itu berarti mau menerima keadaan pasangan dan menyadari kedudukannya sebagai istri. Sebagai istri dia harus menghargai suaminya, bagaimanapun keadaannya. Meski suami tidak tampan, tidak berharta, tidak berkedudukan, atau cacat fisik sekalipun, dia harus tetap menghormati suami. 
Ajaran itu sangat mendalam maknanya. Ajaran yang mengingatkan bahwa ketampanan tidaklah kekal karena akan lekang dimakan usia. Ajaran tersebut juga mengingatkan bahwa harta tidaklah abadi karena jika Allah berkehendak, dalam sekejap akan habis tidak berbekas. Ajaran tersebut juga mengingatkan bahwa kedudukan atau jabatan tidak akan tetap, suatu waktu akan bergeser, berubah, bahkan hilang. Sebaliknya, cacat fisik adalah kondisi fisik yang terbatas. Cacat fisik dapat disebabkan oleh takdir Illahi, tetapi juga karena suatu peristiwa yang dialami. Cacat fisik adalah kekurangan lahiriah yang belum tentu rusak pula batiniahnya. Yang perlu disadari tentang cacat fisik adalah bahwa tidak ada seorang manusia pun di dunia ini yang ingin dilahirkan tidak sempurna. Yang perlu digali dengan ketidaksempurnaan fisik yang dialami oleh seorang laki-laki adalah kelebihan atau potensi diri yang dimiliknya. Kelebihan yang dimiliki itulah yang dapat menjadi nilai lebih atas cacat fisik yang dialaminya.

Tentang syarat perkawinan yang harus dipenuhi perempuan terlihat di $S W R P$, pupuh Mijil, bait ke-2 sebagai berikut.

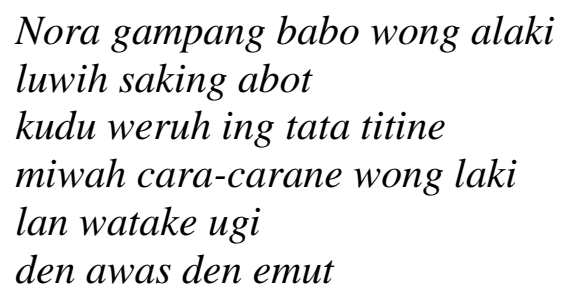

Terjemahan:

Tidak mudah orang bersuami sangat berat harus tahu aturan juga harus tahu cara-cara orang bersuami dan juga watak lelaki waspadalah dan ingatlah

Kutipan SWRP, pupuh Mijil, bait ke-2 di atas memuat ajaran syarat-syarat yang harus dipenuhi oleh seorang perempuan dalam menjalani pernikahannya. Pada kutipan tersebut tersurat bahwa pernikahan adalah hal berat. Pernikahan tidak sekadar menyatukan sepasang anak manusia dalam ikatan pernikahan. Akan tetapi, pernikahan adalah kehidupan baru dengan penyatuan dua individu yang berbeda. Perbedaan itu tidak sekadar pada jenis kelamin saja, tetapi juga perbedaan sifat, perilaku, pendidikan, latar belakang keluarga, atau budaya. 
Kutipan tersebut member petunjuk bahwa menikah adalah hal yang mudah, tetapi untuk menjalani dan mempertahankan pernikahan itu suatu hal yang berat. Banyak cobaan dan godaan untuk menguji keutuhan kehidupan pernikahan. Ujian fisik dan nonfisik itulah yang kadang mendera perempuan sehingga perlu berjuang keras mempertahankan pernikahannya. Hal itu tidak lain dan tidak bukan karena perempuan adalah makhluk yang sangat halus perasaannya.

\title{
Pergaulan Bebas
}

Seorang perempuan harus menjaga diri dan kehormatannya sebelum dan sesudah menjadi istri. Seorang perempuan sangat tidak layak dan tidak dibenarkan untuk menjalin pergaulan bebas dengan laki-laki yang bukan suaminya, lebih-lebih sampai berbuat zina. Apabila ada perempuan sampai berbuat zina, dia sudah mencorengkan arang ke mukanya sendiri. Selain itu, dia juga merusak nama baik orang tua dan keluarganya. Berikut kutipan tentang pergaulan bebas dalam bentuk zina di SWRP, pupuh Asmaradana, bait ke-5.

\author{
Pedhot liwaring pawestri \\ Tan ngamung ken wong azina \\ Ya kang ilang nastitine \\ wong pedhot dherodhot bedhot \\ datan mangan ing ngarah \\ pratandhane nora emut \\ yen laki paitan manah \\ Terjemahan: \\ Perempuan yang rusak, \\ Tidak hanya pada orang berzina \\ Termasuk orang yang tidak berhati-hati (tidak teliti) \\ dinamakan "bejat" moralnya \\ tidak mengenal arah \\ pertanda tidak ingat \\ bahwa berumah tangga bermodalkan hati
}

Bentuk pergaulan ikut berubah bersamaan dengan perubahan zaman. Perubahan bentuk pergaulan tersebut tidak dapat dipungkiri sebagai pengaruh pemahaman yang salah terhadap pandangan bahwa budaya perempuan yang dibatasi ruang geraknya atau dipingit dalam bahasa Jawa menjadikan perempuan terkungkung kebebasannya. Akibatnya, perempuan dapat melakukan kesalahan dengan bergaul 
dengan lawan jenis secara kebablasan. Pada akhirnya mereka terperangkap dalam perbuatan zina.

\section{Kesimpulan}

Serat Wulang Reh Putri merupakan salah satu sastra piwulang, yaitu genre sastra yang berisi ajaran, baik tentang perilaku di masyarakat atau ajaran mengenai cara menggapai kesempurnaan hidup. Teks tersebut merupakan karya Paku Buwana IX dari Surakarta. Karya tersebut berisi ajaran yang dikhususkan untuk para putri.

SWRP merupakan ajaran untuk kaum perempuan terutama bagi para istri. Ajaran dalam teks tersebut mengutamakan kepatuhan kepada suami. Seorang suami merupakan panutan bagi seorang perempuan. Oleh karena itu, segala perintah dan permintaannya harus dituruti. Selain itu, seorang istri juga harus menunjukkan rasa sayang dan hormat kepada suaminya.

Selain ketaatan kepada suami, SWRP juga mengajarkan para perempuan agar menghormati lembaga perkawinan. Seorang perempuan dilarang keras mendekati pergaulan bebas. Pergaulan seperti itu dikhawatirkan membuat seorang perempuan dapat terjerumus ke perzinaan. Sesuatu yang dihujat di masyarakat dan dilarang oleh agama.

\section{Daftar Pustaka}

Marsono dan Waridi Hendrosaputro. 1999. Ensiklopedi Kebudayaan Jawa. Yogyakarta: Lembaga Studi Jawa.

Ratnawati, Sri. 2008. "Perempuan dan Ajaran Perenialis dalam Serat Wulang Putri". Dalam BAHASA DAN SENI, Tahun 36, Nomor 1, Februari 2008.

Siswokartono, W.E. Soetomo. 2006. Sri Mangkunagara IV Sebagai Penguasa dan Pujangga (1853-1881). Semarang: Aneka Ilmu.

Sudewa, Alexander. 1991. Serat Panitisastra. Yogyakarta: Duta Wacana University Press.

Suratno, Pardi. 2006. Sang Pemimpin: dalam Asthabrata, Wulangreh, Tripama, dan Asthadasa Raja. Yogyakarta: Adi Wacana. 